\title{
Self-commissioning of Interior Permanent Magnet Synchronous Motor Drives With High-Frequency Current Injection
}

\author{
S. A. Odhano* \\ Student Member, IEEE \\ P. Giangrande** \\ Member, IEEE \\ * Politecnico di Torino, \\ Corso Duca degli Abruzzi, 24, \\ Torino, 10129, Italy
}

Abstract -In this paper, a simple and robust method for 40 parameter estimation at rotor standstill is presented for interior 41 permanent magnet synchronous machines. The estimated 42 parameters are the stator resistance through dc test, the $\boldsymbol{d} \boldsymbol{q} 43$ inductances using high-frequency injection and the permanent 44 magnet flux by means of a closed-loop speed control maintaining 45 rotor stationary. The proposed method does not require either 46 locking the rotor or additional/special power supplies. The 47 validity of the suggested method has been verified by 48 implementation on two interior permanent magnet motor 48 prototypes. Finally, the estimated parameters have been 50 compared against results obtained through finite element 50 simulations and with machine magnetic characterization, 51 separately performed, to validate the method's effectiveness. 52 Saturation and cross-saturation effects are taken care of through 53 amplitude modulation and cross-axis current application, 54 respectively.

Index terms: variable speed drives, permanent magnet motors, 57 parameter estimation, current control, $\boldsymbol{d q}$-inductances, 58 permanent magnet flux

\section{INTRODUCTION}

Nowadays, Interior Permanent Magnet (IPM) motors are 62 finding ever increasing number of applications in industry due 63 to their high power-density and efficiency $[1,2]$. IPM motors 64 are typically characterized by a wide constant-power operating 65 region and have a rotor structure which makes them capable to 66 reach high speeds [3]. Their application in high-performance 67 control requires well-tuned controllers to the machine's 68 parameters. The knowledge of these parameters is of 69 paramount importance for designing high-performance control 70 and/or developing accurate simulation models. By high- 71 performance control is meant least torque (position) ripple for 72 torque (position) drives and very good machine exploitation. 73 Machine parameters are typically load and temperature 74 dependent. This makes their estimation a challenging task. The 75 parameters' values and variation can be obtained from various 76 tests performed on the machine. Several methods are studied 76 and implemented with their relative advantages and disadvantages. In the scope of self-commissioning of the drive

\author{
R. Bojoi* \\ Senior Member, IEEE \\ C. Gerada** \\ Member, IEEE
}

system, it is desirable that the parameters are estimated at standstill with no special arrangements such as particular supplies, additional measurement probes (e.g. voltage probes), advanced data acquisition systems, machine isolation from its load and so on. The methods of parameter identification for permanent magnet synchronous motors proposed in literature do not all meet these requirements at the same time. For instance, in [4] and [5] the inductances of the orthogonal axes $(d$ and $q$ ) are obtained for a running machine, this may be acceptable for steady state online parameter monitoring/updating, but may not be suitable for start-up commissioning especially if the steady state cannot be reached (cf. actuators). Broadband excitation proposed in [6] identifies machine parameters at standstill, but requires special frequency generators and rotor mechanical locking. Similarly, the method proposed in [7] necessitates rotor mechanical blocking for identification. Although [8] does not require additional signal injection, the method needs a rough estimate of initial parameters anyway. Inductance estimation using [9] requires complete geometrical data of the machine. Of the two methods analyzed in [10], the first requires external AC supplies and the second needs the rotating machine. The $d$-axis inductance identification strategy of [11] is compatible with the definition of self-commissioning, however, the cross-saturation effects and other machine parameters are not determined in this work. Other solutions on parameter estimation include [12-16].

This paper presents a simple and robust self-commissioning method for IPM motors at standstill. The identified parameters are the stator resistance, the $(d, q)$ inductances and the magnets flux linkage. The paper main contribution is related to the identification of the $(d, q)$ inductances through high frequency injection that takes into account the saturation and crosssaturation effects. Moreover, the permanent magnet flux-linkage is estimated using a torque balancing strategy in which the magnet alignment torque is balanced by the reluctance torque. All the restrictions imposed by the definition of self-commissioning, i.e. estimation of machine parameters at standstill without additional test equipment, are respected. 
The proposed method for the estimation of $(d, q) 53$ inductances can be applied for IPM motors and also for 54 Synchronous Reluctance (SyncRel) motors. The method 55 proposed for the identification of the magnets flux linkage can 56 only be used for IPM motors exhibiting high saliency ratio.

The test signals are generated through the voltage source 58 inverter (VSI) supplying the machine in normal operating 59 conditions and do not require any other measurement apart 60 from the stator phase currents and dc-link voltage. The rotor 61 position is also needed and must be measured through a position sensor. Injecting zero-centered high-frequency currents does not produce any torque that would tend to rotate 62 the machine and therefore no rotor mechanical locking is required, nor is it necessary to detach the motor shaft from the 63 load to carry out the commissioning procedure. The entire estimation process can be embedded in machine control and 64 made fully automatic.

The algorithm is verified on two different IPM machines: a 66 $30 \mathrm{~kW}$ traction machine (Mot-1) and a $7 \mathrm{~kW}$ motor (Mot-II). The two machines are markedly different with regards to 67 saliency and speed ranges.

\section{PARAMETER IDENTIFICATION}

\section{A. High frequency injection}

The basis of the proposed method is a high-frequency 72 sinusoidal current injection, which is frequently used in 73 connection with PM motors [17]. The injection in self-axis 74 through current regulators takes place while keeping a constant 75 current in the cross-axis. For a given amplitude and frequency 76 of the injected current signal along one axis (e.g. $d$-axis), the 77 controller output voltage (reference voltage) is observed; these 78 voltage and current values are then used to estimate the total 79 impedance of that axis. The current controllers can be tuned a 80 priori through gain scheduling.

The signal injection frequency is limited by the 83 proportional-integral (PI) current controller bandwidth that in turn depends on inverter switching frequency. For this reason, the standard PI current controller, which would require a high bandwidth, is substituted by a proportional-integral controller plus resonant term (PI-RES). From the active power filters applications [18], it is known that the resonant current regulators give optimum performance, since the resonant term ensures accurate tracking of the injected sinusoidal signal.

While the amplitude of maximum injected current depends on machine rated phase current, the injection frequency is limited by inverter switching frequency. At extremely low frequencies, the imaginary part of the controller voltage corresponding to inductive drop is too small to give a reliable reading, whereas at excessively high injection frequencies, the skin effect weighs in. For this reason, the injected frequency is 84 kept around nominal operating frequency of the machine. Tests 85 at machine operating frequency resemble single-phase testing, however, in single-phase tests a nominal frequency voltage is applied in one of the phases regardless of rotor position; with high-frequency current injection in $d$-axis, the rotor position is taken into account so that the impedance seen by the injected current is precisely the $d$-axis impedance.

\section{B. Resistance and inductances estimation}

The $d$ - and $q$-axis equivalent circuits of an IPMSM are shown in Figure 1, with iron-losses neglected. The machine dynamic equations in $(d, q)$ rotating reference frame are given in (1) and (2).

$$
\begin{gathered}
v_{d}=R \cdot i_{d}+L_{d} \frac{d i_{d}}{d t}-\omega \cdot \lambda_{q} \\
v_{q}=R \cdot i_{q}+L_{q} \frac{d i_{q}}{d t}+\omega \cdot \lambda_{d}^{\prime}+\omega \cdot \lambda_{m}
\end{gathered}
$$

where $\omega$ is the electrical rotor speed, $R$ is the stator resistance, $L_{d}$ and $L_{q}$ are the inductances along the $d$ - and $q$-axis respectively, $i_{d}$ and $i_{q}$ are the $d$ - and $q$-axis currents, $\lambda_{d}^{\prime}$ and $\lambda_{q}$ are the flux-linkages due to $d$ - and $q$-axis currents, respectively, and $\lambda_{m}$ is the permanent magnet flux.

In the proposed method, the first parameter to be estimated is the stator resistance. The widely accepted and commonly used way of detecting the stator resistance of any electrical machine is the dc injection test [19], the same is applied here to determine this parameter. Although [19] prescribes this test for induction motor drive, it can be used for IPMSM since the stator windings of nearly all ac machines are identical. The $d$-axis current controller is used to inject a reference dc current inside the machine and the voltage obtained from the controller is used to estimate the stator resistance. During the dc injection test, the current is injected along the $d$-axis for preventing the rotor rotation. In order to make the estimation immune to the inverter non-linearity effects, two levels of current are applied and the resistance is estimated from the difference of voltage and the current, as shown in (3).

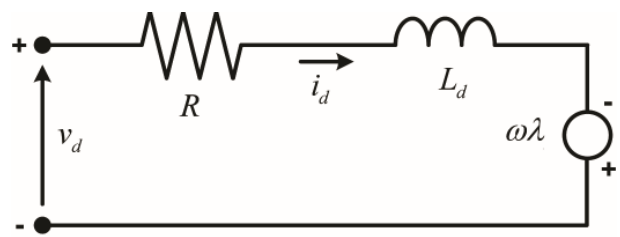

(a)

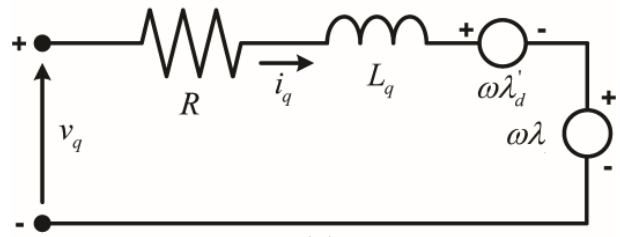

(b)

Figure 1: $d$-axis (a) and $q$-axis (b) equivalent circuits 


$$
R=\frac{V_{2}-V_{1}}{I_{2}-I_{1}}
$$

Estimated the stator resistance, let's consider the 43 developed electromagnetic torque, which is given by: 45

$$
T=T_{r e l}+T_{m a g}=\frac{3}{2} \cdot p \cdot\left(L_{d}-L_{q}\right) \cdot i_{d} \cdot i_{q}+\frac{3}{2} \cdot p \cdot i_{q} \cdot \lambda_{m} \text { (4) } \begin{array}{r}
46 \\
48
\end{array}
$$

where $p$ is the number of machine pole pairs. $\quad 50$

Equation (4) indicates that the electromagnetic torque has two components: the reluctance torque (first term on right- 52 hand-side) and the alignment torque (second term). From (4), 53 it is evident that if the average value of applied $d$-and $q$-axis 54 currents is zero, as will be the case here with balanced 55 sinusoidal current application, the developed torque is zero. It 56 is due to this nature of applied signals that the rotor locking is 57 ruled out and the rotor continues to remain stationary. This is 58 consistent with the definition of self-commissioning in 'any' 59 motor-load setting. With the rotor at standstill, $\omega$ is equal to 60 zero; equations (1) and (2) simplify to those of simple $R L 61$ series circuit and completely decoupled from each other. In 62 other words, all the cross terms in which the rotor speed 63 appears become equal to zero.

With the application of a sinusoidal current of known 65 magnitude along $d$-axis through the PI-RES current controller, 66 the $d$-axis current controller output voltage can be written in 67 phasor notation as:

$$
Z_{d}=R+j X_{d}=R+j 2 \pi f_{i n j} L_{d}
$$

where $f_{i n j}$ is the frequency of the injected current.

Similarly, for the $q$-axis:

$$
\begin{gathered}
\bar{V}_{q}^{*}=Z_{q} \bar{I}_{q} \\
Z_{q}=R+j 2 \pi f_{i n j} L_{q}
\end{gathered}
$$
where $\bar{V}_{d}^{*}$ and $\bar{V}_{q}^{*}$ are the phasors obtained from the current 84 controllers (voltage references).

The impedances along the two orthogonal axes are 87 computed as ratio between the voltage reference component at 88 injection frequency (which is obtained through the Fourier analysis of the controller output) divided by the injected 89 current. It may be argued that the resistance of the machine 90 does vary with varying injection frequency due to skin effect; 91 however, the same is taken care of while separating the real 92 and imaginary parts of the impedance through phase angle 93 between controller voltage and $d$ - or $q$-axis current. Using a PI-RES current controller, the sinusoidal machine current is ensured, while the voltage reference does not have a sinusoidal waveform. The voltage harmonics are eliminated performing the real-time Fourier analysis on the voltage reference signal; hence the voltage reference component at injection frequency is isolated. Although the inverter nonlinearity effects can be compensated from the available inverter dead-time data, they do not pose any significant problem in estimating inductances, because they affect only the real part of the impedance vector [20], which is the resistance that is already estimated (through the dc test).

\section{Saturation and cross-saturation effects}

A non-ideal iron core traced by winding ampere-turns can sustain a certain flux level beyond which it saturates and a further increase in current will not produce any significant flux increment, the phenomenon is termed magnetic saturation. Saturation effects in permanent magnet machines are as important as they are in any other ac machine. The presence of permanent magnet flux contributes in this phenomenon, that results in decrement in machine inductances (namely $L_{d}$ and $L_{q}$ ) $[7,21]$. In this paper, the effects of magnetic saturation caused by current in self-axis (either $d$ or $q$ ) on the inductance of the same axis are evaluated through amplitude variation of the injected high-frequency signal. The influence of the magnetic saturation on the self-inductances is shown in the experimental results section.

A further phenomenon, which has been considered in the analysis presented here, is the cross-coupling effect. Sharing a common ferromagnetic core, the currents in the two orthogonal axes of an ac machine interact in affecting the flux and hence inductance in the perpendicular axis, this effect is explained as the redistribution of flux due to core saturation and is called cross-coupling or cross-saturation effect $[22,23]$. Starting with zero current in the cross-axis, this current is then increased to take into account the cross-coupling effects on inductances between the two axes. This approach does not produce electromagnetic torque when the $d$-axis is assumed as crossaxis; on the other hand, non-zero current component along the $q$-axis will generate alignment torque. Rotor rotation can be avoided by cancelling out the alignment torque exploiting the reluctance torque by an appropriate constant $d$-axis current superimposed on the applied high-frequency signal. However, a constant $d$-axis current component may alter the machine magnetization state and thus pollute the estimation, a way around is to apply a square wave $i_{q}$ whose frequency is high enough as to not cause any rotation and sufficiently low to not interfere with $i_{d}$ injection. This strategy of square wave $q$-axis injection is used in this work.

\section{Permanent magnet flux-linkage estimation}

The impact of permanent magnet flux linkage $\left(\lambda_{m}\right)$ on machine torque production is significant and its correct value is required for high performance torque/position drives. The traditional method of rotating the machine at no-load and 
analyzing the back-emf induced in stator windings entails 44 (i) mechanical decoupling of machine from load, (ii) the need 45 of a prime-mover and (iii) terminal voltage measurement 46 instrument(s). Thus, alternatives to this traditional test are 47 required. Whereas the methods proposed in [24, 25] give 48 estimates of permanent magnet flux linkage for a machine in 49 operation, standstill estimation is focused here, in order to be 50 consistent with self-commissioning definition.

As said in section II.B, the induced torque has two 52 components: alignment and reluctance torque. If a constant $i_{q}$ is 53 applied, the machine tends to rotate due to alignment torque, 55 however, if $i_{d}$ is controlled such that the reluctance torque is equal and opposite to alignment torque, the rotor continues to be at rest, since the resulting torque is equal to zero. Equating (4) to zero and solving for $i_{d}$ gives (9). Figure 2 shows the variation of electromagnetic torque $\left(T_{n e t}\right)$ and its components, such as alignment torque $\left(T_{m a g}\right)$ and reluctance torque $\left(T_{r e l}\right)$, as function of the current angle $\gamma$ at a given current magnitude $(I)$ for the machine Mot-II. The current angle $\gamma$ is defined as shown in Figure 3. For a certain value of $\gamma\left(\right.$ approx. $\left.-40^{\circ}\right)$ at the particular current $I$, the net torque of Mot-II is zero. From controller output $i_{d}^{*}$ and knowing the inductances $L_{d}$ and $L_{q}$ from high-frequency tests, the PM flux linkage can be computed, by equating (4) to zero since the resulting electromagnetic torque $\left(T_{n e t}\right)$ is null, as shown in (10). Care must be taken that $L_{d}$ and $L_{q}$ should correspond to the values of $i_{d}$ and $i_{q}$ at which the torque balance is achieved to get correct $\lambda_{m}$ estimate from (9).

$$
\begin{gathered}
i_{d}^{*}=-\frac{\lambda_{m}}{\left(L_{d}-L_{q}\right)} \\
\lambda_{m}=-i_{d}^{*}\left(L_{d}-L_{q}\right)
\end{gathered}
$$

In order to perform this test, the control scheme depicted in Figure 4 has been adopted. A closed-loop speed control, with zero reference signal, is implemented, while a non-zero current reference signal is applied along the $q$-axis $\left(i_{q}^{*} \neq 0\right)$. In these conditions, the PI speed controller will generate an output $\left(i_{d}^{*}\right)$ that keeps the rotor stationary by producing enough reluctance torque to counteract the alignment torque caused by the $q$-axis current.

Theoretically, $i_{d}$ is independent of $i_{q}$ as can be seen in (9), practically it is not the case. As $i_{q}$ increases, $L_{q}$ decreases and the controller output for $i_{d}$ increases to compensate for $L_{q} 60$ decrement. A higher $i_{d}$ causes a reduction in $L_{d}$ further increasing $i_{d}$ till a balance is achieved. Therefore, for every $i_{q} 61$ there exists a unique $i_{d}$ for torque balance. The controller output should be limited anyway to respect the phase current limit. It is worth a mention here that this method works only for machines having reluctance torque comparable to the alignment torque (high-saliency machines). It can be applied to low saliency machines provided the saturation-induced saliency is high. Saturation induced saliency occurs in machines in which the $d$-axis flux path is nearly saturated only due to the flux of the permanent magnets and any positive current along the d-axis drives the machine into saturation thus causing a reduction in $L_{d}$ and hence increasing the saliency ratio.

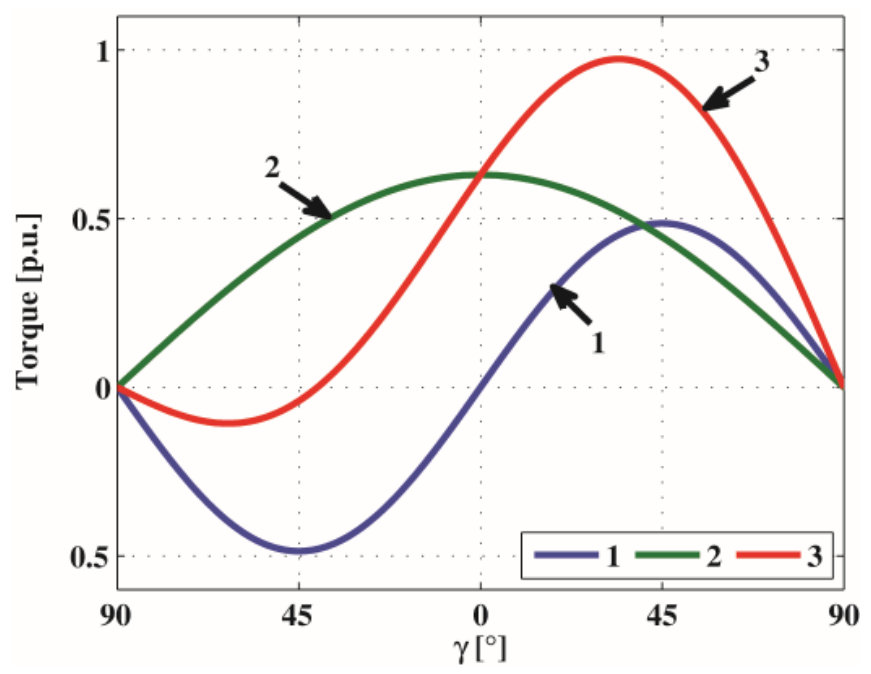

Figure 2: Torque components in IPM (Mot-II): (1) reluctance torque $\left(T_{r e l}\right),(2)$ alignment torque $\left(T_{\text {mag }}\right)$, and (3) resulting torque $\left(T_{\text {net }}\right)$

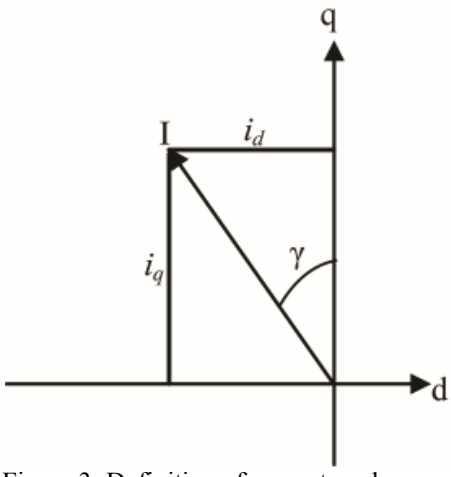

Figure 3: Definition of current angle $\gamma$ 


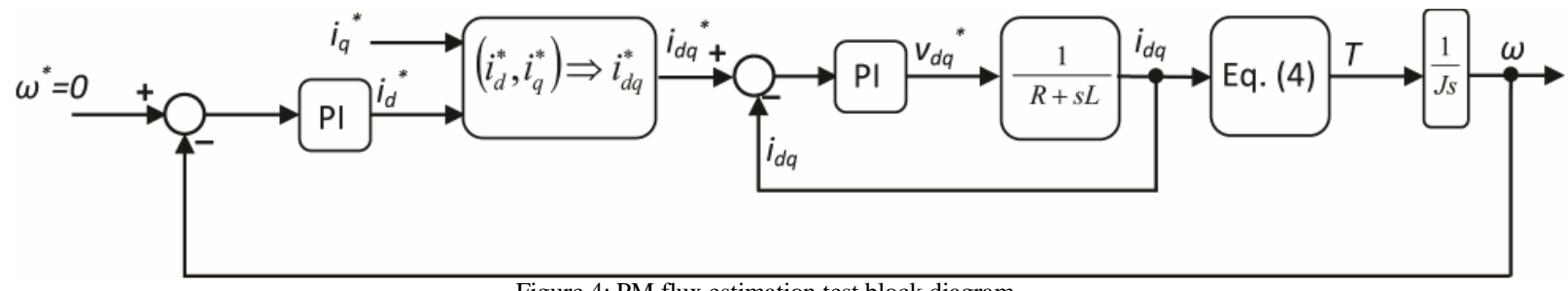

Figure 4: PM flux estimation test block diagram

\section{EXPERIMENTAL SETUP}

The block diagram of the drive system is shown in 45 Figure 5. As already mentioned, the current loops adopt a 46 standard PI current controller plus resonant term (PI-RES), in 47 order to ensure the accurate tracking of both the dc and high- 48 frequency sinusoidal components. The experimental setup 49 consists of a Eurotherm drive system 584SV controlled 50 through a dSpace DS1104 PPC (Power PC) controller board. 51 This is used for control execution, command generation and 52 data acquisition. A slave digital signal processor (DSP) 53 TMS320F240 of the dSpace microcontroller board generates 54 PWM switching commands for the power switches. The carrier 55 frequency for PWM generation is set as $5 \mathrm{kHz}$ and the data 56 acquisition is synchronous with the PWM interrupt, i.e. the 57 data sampling time is $200 \mu \mathrm{s}$. The proposed parameters 58 identification algorithm has been implemented on two IPMSMs. The first motor under test, named Mot-I, is a traction motor rated at $30 \mathrm{~kW}$, having 16 poles, 24 slots, $1300 \mathrm{rpm}$ (base speed), $2800 \mathrm{rpm}$ (maximum reachable speed with fluxweakening). The position information is measured using an incremental encoder with 4096 pulses per revolution. Figure 6 depicts the test bench for this machine, it is evident that the rotor shaft is free to rotate and no locking device is adopted. The IPMSM is mechanically coupled to a dc motor; nevertheless the latter is not used during the tests. The second 59 machine (named Mot-II), used in the proposed estimation 60 method, is a $7 \mathrm{~kW}$ motor and its specifications are reported in [26].

\section{EXPERIMENTAL RESULTS}

The stator resistance has been estimated using the method explained in section II.B. Figure 7 reports the applied current step along the $d$-axis and the controller output reference voltage $\left(v_{d}^{*}\right)$ for stator resistance estimation of Mot-I. Using (3), the estimated resistance is equal to $0.0295 \Omega$ and this value is in agreement with the resistance measured with a dc supply by reading voltage and current. Apart from giving the estimate of stator resistance, this dc test can also be used to approximate the voltage drop in power semiconductor switches, as in (11).

$$
\Delta v=V_{1}-R I_{1}=V_{2}-R I_{2}
$$

Mot-I inductances have been estimated by injecting sinusoidal currents at different frequencies along one axis, while the current reference signal is kept equal to zero along the other axis. In Figure 8, the current and voltage waveforms during the test to estimate the $d$-axis self-inductance $\left(L_{d}\right)$ are shown, when $45 \mathrm{~A}$ amplitude current at $175 \mathrm{~Hz}$ (the nominal machine frequency is $173 \mathrm{~Hz}$ ) is injected along the $d$-axis ( $q$-axis current is kept to zero). In particular, the upper plot of Figure 8 shows both reference (trace 1) and measured (trace 2) currents, while the lower plot reports PI-RES controller output voltage $\left(v_{d}^{*}\right)$ (trace 3$)$ and its fundamental (trace 4 ) obtained through Fourier analysis. The trace 3 from Figure 8 shows the distortion in the current controller output voltage, due largely to the inverter non-linearities, which is eliminated by a realtime Fourier analysis.

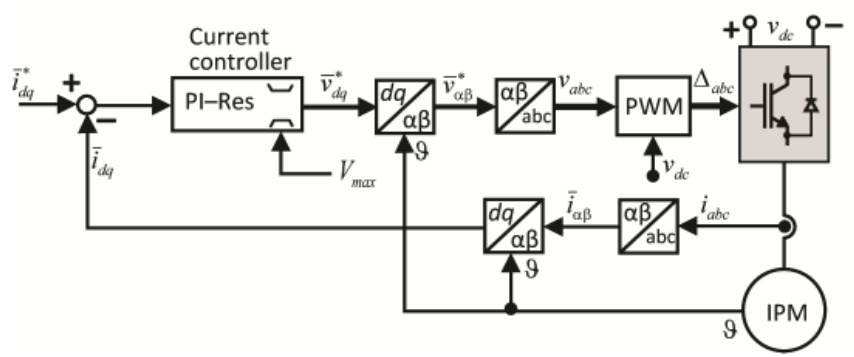

Figure 5: Test drive system block diagram

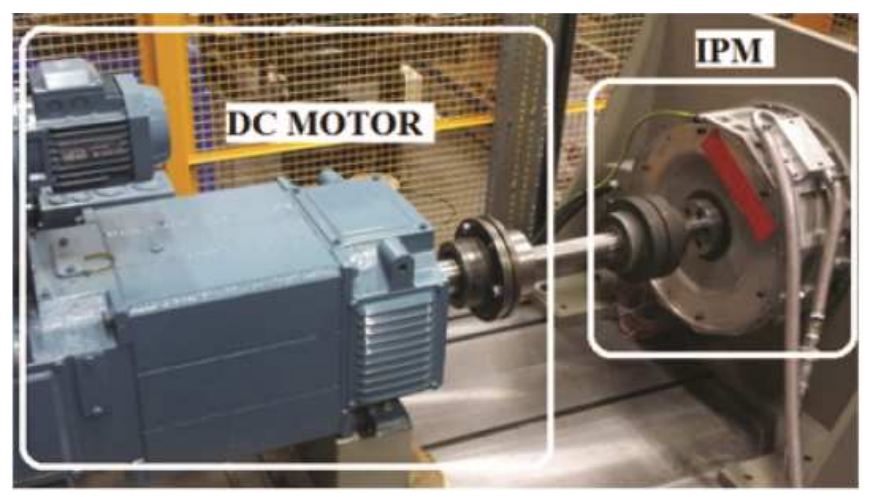

Figure 6: Test bench of the $30 \mathrm{~kW}$ traction motor (Mot-I)

In (11) $R$ is the stator resistance obtained from (3) and $\Delta v$ is the voltage drop across the power switches. This voltage drop is used to purify further the inductance estimation from the inverter non-linearity effects along with Fourier transform. 


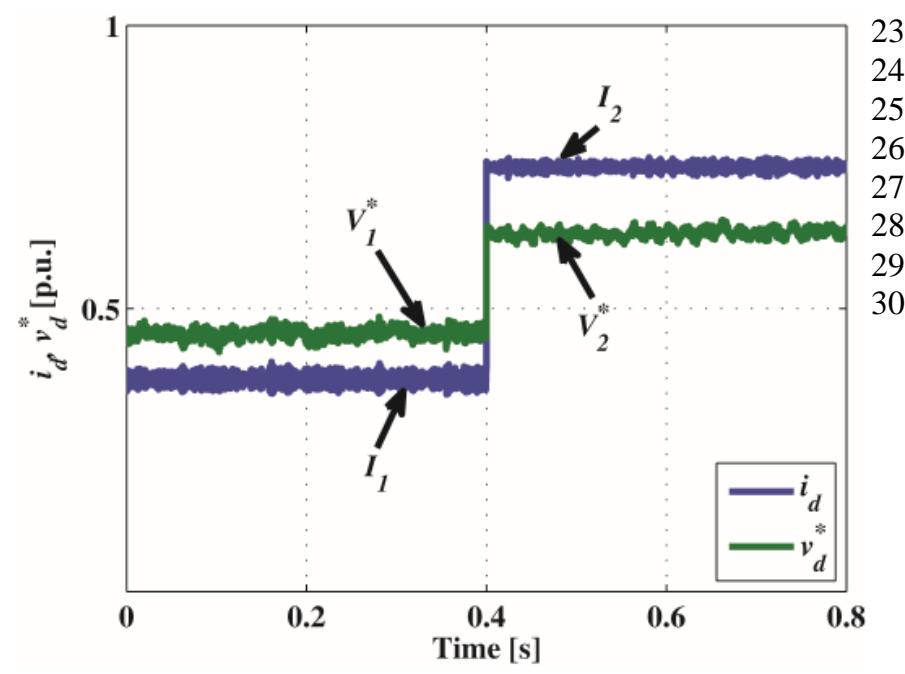

2

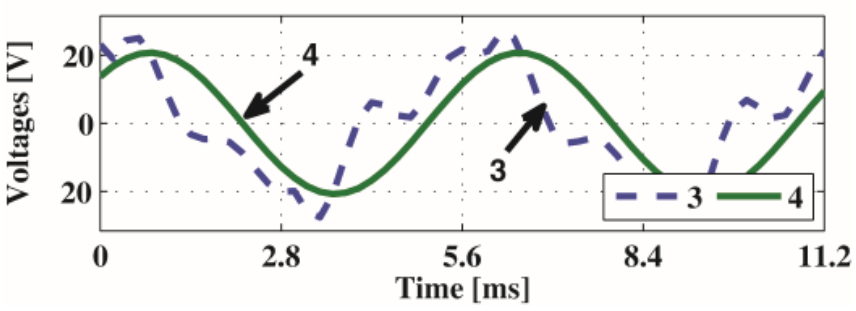

Figure 8: Test performed on Mot-I for estimating $L_{d}$ at $175 \mathrm{~Hz}$. Top axis: (1) $d$-axis reference current, (2) measured $d$-axis current. Bottom axis: (3) PI-RES controller output voltage, (4) its fundamental component

Figure 9 gives the injection results in the $q$-axis to estimate the $q$-axis inductance, when a 45 A current is injected along the $q$-axis, with zero $d$-axis current. The upper plot in Figure 9 shows the reference (trace 1) and measured (trace 2) $q$-axis currents, while the lower plot reports PI-RES controller output voltage (trace 3 ) and its fundamental (trace 4 ) obtained through 35 Fourier analysis. This test gives the value of $q$-axis 36 self-inductance $\left(L_{q}\right)$. The estimated inductances for a given 37 value of current at different frequencies were compared against the inductance values obtained through a finite element 38 analysis (FEA) performed on the machine model in MagNet, in 39 order to validate the experimental inductance measurements. 40 Figure 10 illustrates this comparison.

Magnetic saturation effect on the self-axis inductance is 42 evaluated by varying the amplitude of injected current, while 43 keeping a constant injection frequency. The injection frequency is chosen such that it is close to machine nominal frequency, so that the tests emulate the actual operating conditions of the motor under test. Saturation tests are performed on Mot-II and the results are compared with the available magnetic characterization data of the machine. Mot-II characterization is conducted based on the method described in [27].
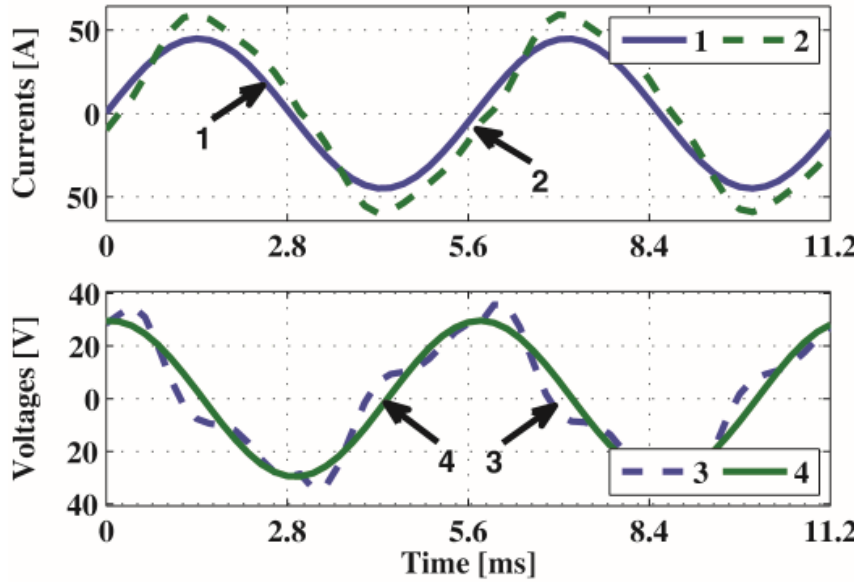

Figure 9: Test performed on Mot-I for estimating $L_{q}$ at $175 \mathrm{~Hz}$. Top axis: (1) $q$-axis reference current, (2) measured $q$-axis current. Bottom axis: (3) PI-RES controller output voltage, (4) its fundamental component

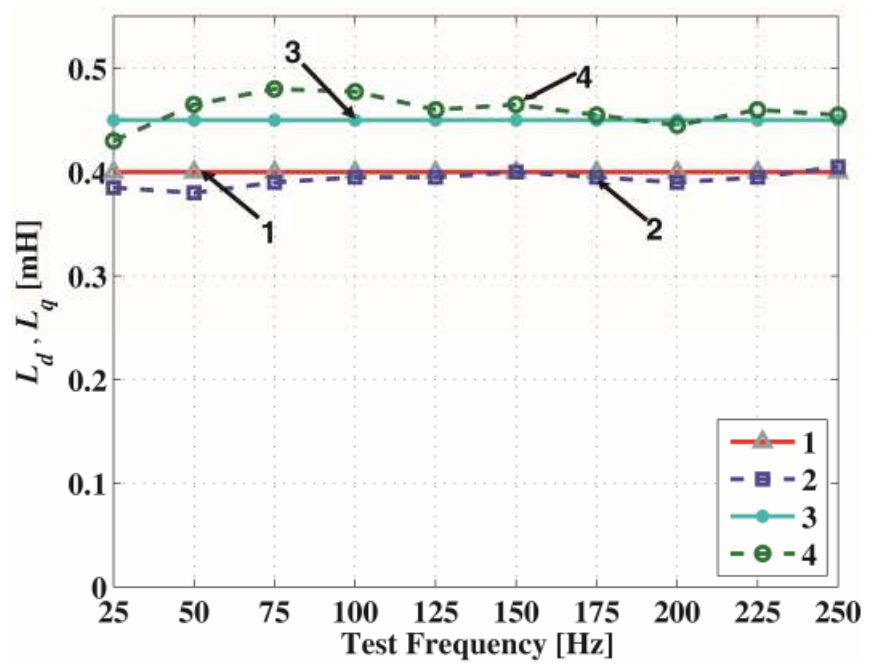

Figure 10: Comparison between experimental and FEA inductances for Mot-I (1) $L_{d}$ (FEA), (2) $L_{d}$ (HF test), (3) $L_{q}$ (FEA), (4) $L_{q}$ (HF test)

As already said, the saturation phenomenon is manifested by a decrease in self-axis inductance with an increase in injected current. Figure 11 highlights the effects of saturation on inductances. The plot shows that the high-frequency inductance estimate for $d$-axis closely follows the magnetic characterization data for increasing $i_{d}$ values. However, in 
$q$-axis the estimate deviates a great deal from the magnetic model; this deviation can be explained on the basis of the 4layer rotor structure of this particular IPM machine shown in Figure 13 ([27]).

The magnetic characterization is recorded for constant $q$-axis currents, in which case once the rotor ribs are saturated, they behave linearly as does air and inductance decreases linearly with current. However, in the high-frequency tests the $q$-axis current varies sinusoidally (with zero-crossings) between one positive peak and one negative peak, so the ribs saturate and desaturate periodically. As the ribs desaturate during current zero-crossings, the inductance increases while it decreases at the positive and negative peaks. The Fourier analysis of the controller output voltage wave takes into account the entire period of the injected wave, the total inductance seen at the stator terminals is slightly higher as seen in Figure 11.

This discrepancy can be avoided in two ways. The first 40 approach uses the positive peak values of the injected current 42 instead of its fundamental obtained through Fourier analysis that takes into account the entire sine wave period. Figure 12 shows the comparison of $q$-axis inductances obtained by considering the fundamental component (trace 3 ) and the ones obtained by using the peak current values (trace 2) with the inductances computed from the magnetic characterization data (trace 1). As it can be seen from Figure 12, the estimated $L_{q}$ improves significantly when only the positive peak current values are used.

The second way is to apply a dc biased ac signal in which the dc bias sets magnetic operating point and the ac signal 43 detects the differential inductance at various bias points. This 44 second strategy is under study and will be presented in a future work.

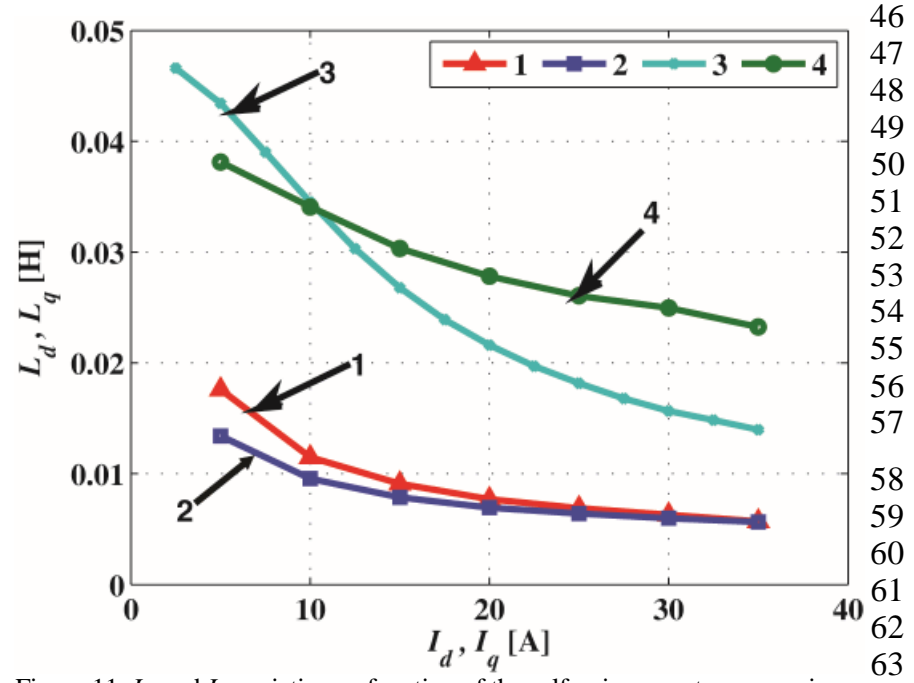

Figure 11: $L_{d}$ and $L_{q}$ variation as function of the self-axis current - comparison 63 $\begin{array}{ll}\text { between proposed method and magnetic characterization for Mot-II: (1) } L_{d} & 64 \\ \text { (magnetic characterization), (2) } L_{d} \text { (HF test), (3) } L_{q} \text { (magnetic characterization), } & 65\end{array}$ $\begin{array}{cc}\text { (magnetic characterization), (2) } L_{d} \text { (HF test), (3) } L_{q} \text { (magnetic characterization), } & 65 \\ \text { (4) } L_{q} \text { (HF test) } & 66\end{array}$

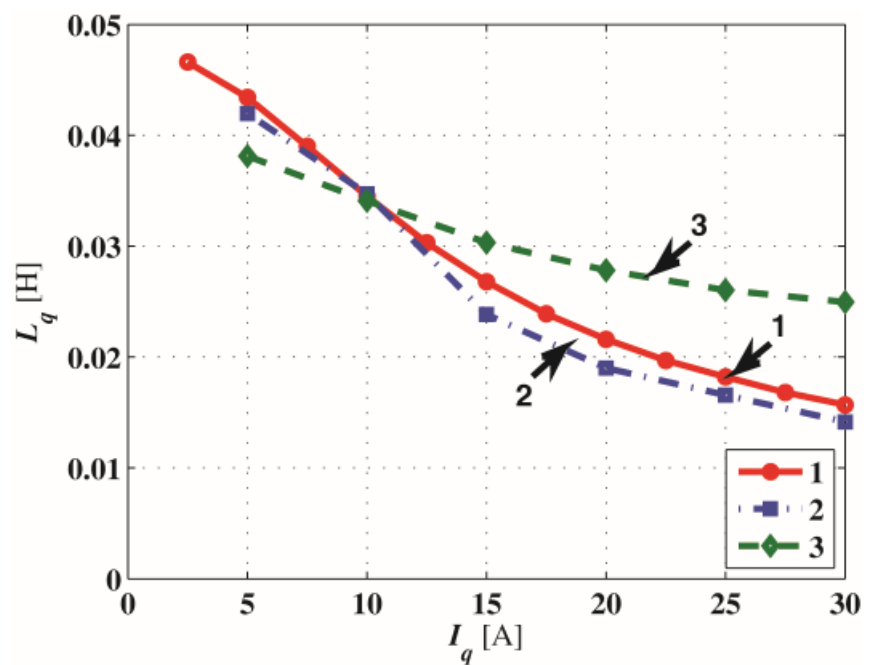

Figure 12: Lq variation with iq: (1) magnetic characterization data, (2) HF test considering peak current values, (3) HF test using the fundamental obtained through Fourier analysis

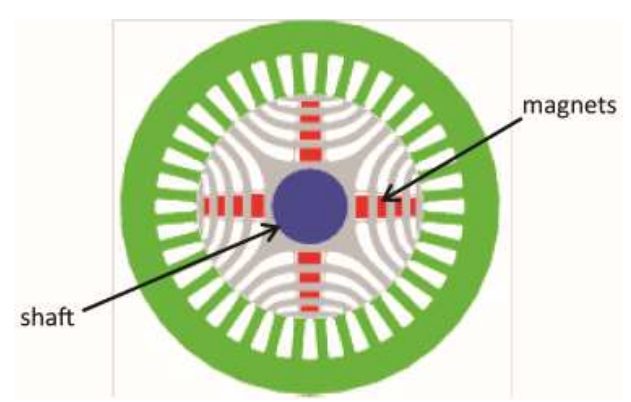

Figure 13: Rotor structure for Mot-II ([27])

As far as the cross-saturation is concerned, two ways of evaluation are examined. In the first case, the controller output voltage is observed in the cross-axis for a certain injection in self-axis. The cross-saturation acts in such a way that when a sinusoidal current is injected in one axis (e.g. $d$-axis), while keeping zero reference current for the cross-axis (e.g. $q$-axis), the output of the cross-axis controller experiences a disturbance to keep the current in the cross-axis to zero. This disturbance is quantified for various current amplitudes to compute cross-coupling inductances. The second approach is as explained in section II.C i.e. applying a constant current in cross-axis and high-frequency injection in self-axis; the results presented here are obtained with this approach.

As earlier mentioned, the technique of using square wave $q$-axis current instead of constant current to prevent rotation has been adapted for verifying the cross-saturation effects on the $d$-axis. Figure 14 shows both the sinusoidal current injected along the $d$-axis, and the square waveform current applied in the $q$-axis. It can be observed that the square waveform frequency is far lower than the frequency of sinusoidal waveform injected along the $d$-axis. Using this approach, it is possible to evaluate the cross-saturation effect on $L_{d}$, having a 
non-zero current along the $q$-axis and a zero rotor speed, since the average value of $i_{q}$ is equal to zero. This method provides more reliable results than the previous one. However, for evaluating the cross-saturation effects on $L_{q}$, a constant $d$-axis current was used, since it does not produce any torque of its own for zero average value of $i_{q}$. For Mot-II, the effect of the cross-saturation on $L_{d}$ and $L_{q}$ has been evaluated for several values of $i_{q}$ and $i_{d}$ magnitude respectively. The experimental results of this analysis have been compared with those obtained with magnetic characterization, as reported in Figures 15 and 16. In particular, Figure 15 compares the $d$-axis inductance variation with magnetic model data, while Figure 16 does the same for $q$-axis inductance. The two figures show both self-axis saturation and cross-saturation effects.

The permanent magnet flux $\left(\lambda_{m}\right)$ at standstill is estimated by a closed-loop speed control as discussed in section II.D. Figure 4 shows the block diagram of the described control 38 strategy. Speed reference signal is set equal to zero, so that the 40 machine does not rotate during the test. The value of current $i_{q} 41$ is known and that of $i_{d}$ is read from the speed controller's output at which the torque balance is achieved. At these particular values of $i_{d}$ and $i_{q}$, the machine's inductances $L_{d}$ and $L_{q}$ are obtained from Figure 15 and 16 respectively. Then equation (10) is used to compute $\lambda_{m}$. The speed regulator gains are usually known if the machine is connected to a given load, if not then they can be obtained through gain scheduling (as discussed for current regulators above). Since the method works only for machines having considerable reluctance torque, the method could not be applied to Mot-I whose reluctance is just $21 \%$ of the alignment torque. However, for Mot-II this method provides a good estimate of $\lambda_{m}$. The permanent magnet flux from the back-emf test of the machine (Mot-II) is $0.07 \mathrm{Vs}$ whereas the value obtained with this test is 0.065 Vs.

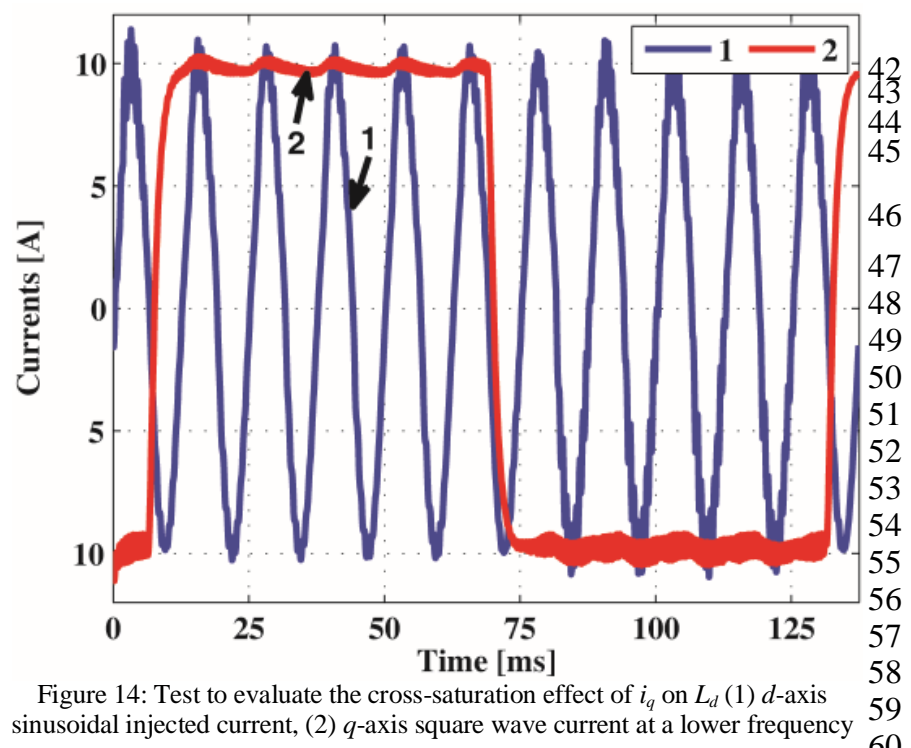

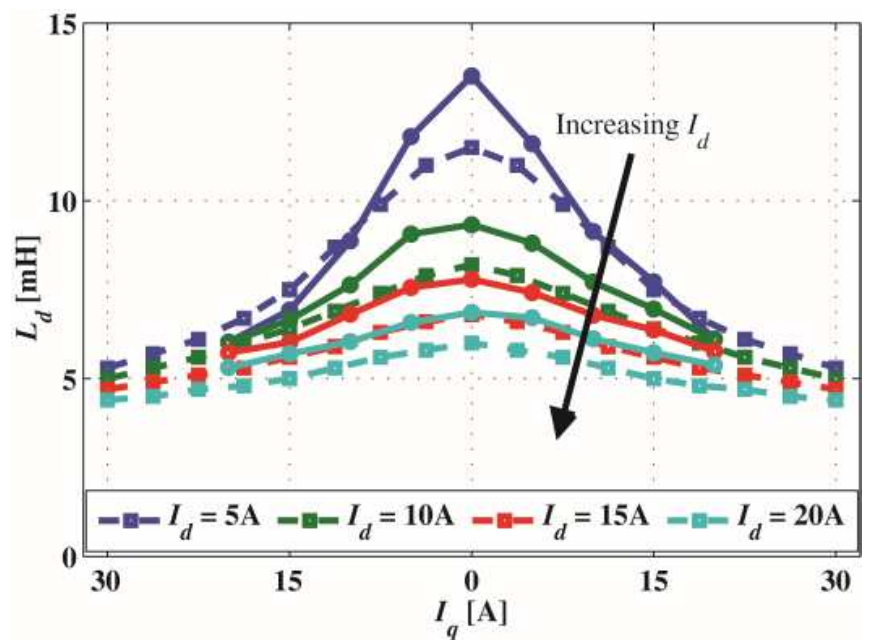

Figure 15: Cross-saturation effects of $i_{q}$ on $L_{d}$ (Mot-II): comparison between high-frequency test results (continuous line) and magnetic characterization results (dashed line) for several injected $i_{d}$ values

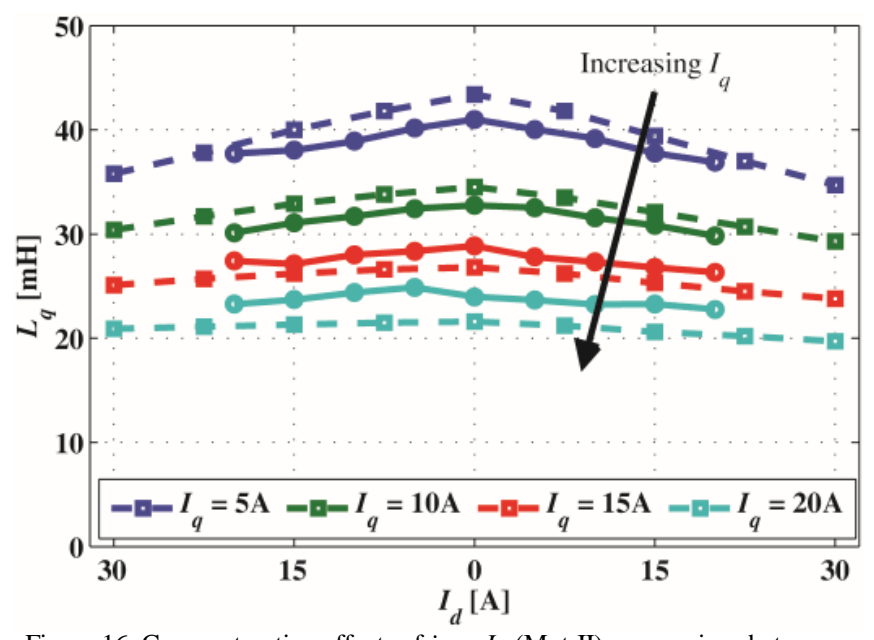

Figure 16: Cross-saturation effects of $i_{d}$ on $L_{q}$ (Mot-II): comparison between high-frequency test results (continuous line) and magnetic characterization results (dashed line) for several injected $i_{q}$ values

\section{CONCLUSIONS}

A self-commissioning method of IPM motors is presented in this paper, using a new technique based on high-frequency injection for the identification of $d$ - and $q$-axis inductances. Results from experimental tests for self-axis inductances are compared with finite element simulations for stating the invariance with injection frequency. The magnetic saturation and cross-saturation effects typically present in IPM machines are evaluated and the impact on machine inductances is quantified. The proposed method for inductances identification does not require additional hardware and it can be applied to other permanent magnet machines, although all the presented experiments have been performed on IPM machines only. To complete the self-commissioning procedure, the stator resistance is estimated through dc 
injection tests and the permanent magnet flux is estimated 35 through a closed-loop speed control.

APPENDIX

\begin{tabular}{l|c|c|c}
\hline \multicolumn{4}{c}{ Machines' Data } \\
\hline \multicolumn{1}{c}{ Quantity } & Unit & Mot-I & Mot-II \\
\hline Rated power & $\mathrm{kW}$ & 30 & 7 \\
\hline Peak power & $\mathrm{kW}$ & 60 & 10 \\
\hline Pole-pairs & -- & 8 & 2 \\
\hline Base speed & $\mathrm{rpm}$ & 1300 & 2450 \\
\hline Max. speed & $\mathrm{rpm}$ & 2800 & 10,00 \\
& & & 0 \\
\hline$R_{s}$ & $\Omega$ & 0.0295 & 0.3 \\
\hline$L_{d}$ (unsaturated) & $\mathrm{mH}$ & 0.4 & 4 \\
\hline$L_{q}$ (unsaturated) & $\mathrm{mH}$ & 0.45 & 40 \\
\hline$\lambda_{m}$ & $\mathrm{Vs}$ & 0.084 & 0.064 \\
\hline \multicolumn{4}{|c|}{ Inverter Data } \\
\hline Peak current & $\mathrm{A}$ & 90 & 40 \\
\hline DC-link voltage & $\mathrm{V}$ & 380 & 350 \\
\hline
\end{tabular}

\section{REFERENCES}

[9] A. Tessarolo, "Accurate Computation of Multiphase Synchronous Machine Inductances Based on Winding Function Theory," Energy Conversion, IEEE Transactions on, vol. 27, pp. 895-904, 2012.

[10] R. Dutta and M. F. Rahman, "A Comparative Analysis of Two Test Methods of Measuring d- and q-Axes Inductances of Interior Permanent-Magnet Machine," Magnetics, IEEE Transactions on, vol. 42, pp. 3712-3718, 2006.

[11] M. Carraro, et al., "Estimation of the direct-axis inductance in PM synchronous motor drives at standstill," in IEEE International Conference on Industrial Technology, ICIT'13, 2013, pp. 313-318.

[12] S. Ichikawa, et al., "Sensorless Control of Permanent-Magnet Synchronous Motors Using Online Parameter Identification Based on System Identification Theory," IEEE Transactions on Industrial Electronics, vol. 53, p. 10, 03 April 20062006.

[13] M. A. Jabbar, et al., "DETERMINATION OF PARAMETERS FOR INTERNAL PERMANENT MAGNET SYNCHRONOUS MOTORS," presented at the IEEE International Conference on Electrical Machines and Drives - 2005, San Antonio, TX, USA, 2005.

[14] M. Khov, et al., "On-Line Parameter Estimation of PMSM in Open Loop and Closed Loop," presented at the IEEE International Conference on Industrial Technology ICIT - 2009, Gippsland, Victoria, Australia, 2009.

[15] S. Tao, et al., "An improved AC standstill inductance test method for interior PM synchronous motor considering cross-magnetization effect," in Electrical Machines and Systems, 2009. ICEMS 2009. International Conference on, 2009, pp. 1-6.

[16] S. Weisberger, et al., "Estimation of Permanent Magnet Motor Parameters," presented at the IEEE Industrial Applications Conference 1997, New Orleans, USA, 1997.

[17] K. Sungmin, et al., "Maximum Torque per Ampere (MTPA) Control of an IPM Machine Based on Signal Injection Considering Inductance Saturation," Power Electronics, IEEE Transactions on, vol. 28, pp. 488-497, 2013.

[18] R. I. Bojoi, et al., "Current control strategy for power conditioners using sinusoidal signal integrators in synchronous reference frame," Power Electronics, IEEE Transactions on, vol. 20, pp. 1402-1412, 2005.

[19] A. M. Khambadkone and J. Holtz, "Vector-controlled induction motor drive with a self-commissioning scheme," Industrial Electronics, IEEE Transactions on, vol. 38, pp. 322-327, 1991.

[20] A. Bünte and H. Grotstollen, "Offline Parameter Identification of an Inverter-Fed Induction Motor at Standstill," presented at the EPE 1995, Sevilla, 1995.

[21] J. G. Cintron-Rivera, et al., "A simplified characterization method including saturation effects for permanent magnet Machines," in Electrical Machines (ICEM), 2012 XXth International Conference on, 2012, pp. 837-843.

[22] B. Sneyers, et al., "Field Weakening in Buried Permanent Magnet AC Motor Drives," Industry Applications, IEEE Transactions on, vol. IA-21, pp. 398-407, 1985. 
[23] P. Vas, et al., "Cross-Saturation in Smooth-Air-Gap Electrical 12 Machines," Power Engineering Review, IEEE, vol. PER-6, pp. 37- 13 37, 1986.

14

[24] R. Krishnan and P. Vijayraghavan, "Fast estimation and 15 compensation of rotor flux linkage in permanent magnet synchronous 16 machines," in Industrial Electronics, 1999. ISIE '99. Proceedings of 17 the IEEE International Symposium on, 1999, pp. 661-666 vol.2. 18

[25] X. Xi, et al., "Dynamic Permanent Magnet Flux Estimation of 19 Permanent Magnet Synchronous Machines," Applied 20 Superconductivity, IEEE Transactions on, vol. 20, pp. 1085-1088, 21 2010 .
[26] G. Pellegrino, et al., "Direct Flux Field-Oriented Control of IPM Drives With Variable DC Link in the Field-Weakening Region," Industry Applications, IEEE Transactions on, vol. 45, pp. 16191627, 2009.

[27] E. Armando, et al., "Experimental Identification of the Magnetic Model of Synchronous Machines," Industry Applications, IEEE Transactions on, vol. PP, pp. 1-1, 2013. 